\title{
Epidemiology of cardiovascular diseases in Europe
}

\author{
Daan Kromhout* \\ Division of Public Health Research, National Institute of Public Health and the Environment, Bilthoven, the \\ Netherlands
}

\begin{abstract}
Within Europe large differences exist in mortality from coronary heart disease and stroke. These diseases show a clear West-East gradient with high rates in Eastern Europe. In spite the decreasing trend in age-adjusted cardiovascular disease mortality in Western European countries an increase in the number of cardiovascular patients is expected because of the ageing of the population. Consequently the health care cost for these diseases will increase.

Total and HDL cholesterol are major determinants of coronary heart disease. Saturated and trans fatty acids have a total and LDL cholesterol elevating effect and unsaturated fatty acids a lowering effect. N-3 polyunsaturated fatty acids seem to have a protective effect on coronary heart disease occurrence independent of their effect on cholesterol.

Dietary antioxidants could be of importance because they may prevent oxidation of the atherogenic cholesterol rich LDL lipoproteins. There is however no convincing evidence that either vitamin $\mathrm{E}$, carotenoids or vitamin $\mathrm{C}$ protect against coronary heart disease. Observational research has shown that flavonols, polyphenols with strong antioxidant properties present in plant foods, may protect against coronary heart disease.

Blood pressure is a major determinant of coronary heart disease and stroke. Historically salt is viewed as the most important dietary determinant of blood pressure. Recent research shows that also a low-fat diet rich in potassium, calcium and magnesium lowers blood pressure substantially. This suggests a multifactorial influence of different nutrients on blood pressure.

It can be concluded that a diet low in saturated and trans fatty acids and rich in plant foods in combination with regular fish consumption is associated with a low risk of cardiovascular mortality.
\end{abstract}

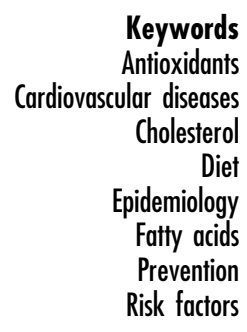

\section{Introduction}

In most European countries cardiovascular diseases contribute about $40 \%$ to all cause mortality. Within this category of diseases the two most important ones are coronary heart disease and stroke. Coronary heart disease contributes about $50 \%$ to total cardiovascular diseases and stroke about $25 \%$. In this chapter the epidemiology of both coronary heart disease and stroke will be described.

Systematic studies on the epidemiology of cardiovascular diseases e.g. the Framingham Study in the USA and the Seven Countries Study were initiated about 50 years ago. An enormous literature on the epidemiology of cardiovascular diseases is available. In this chapter the epidemiology of these diseases will be succinctly summarised with an emphasis on dietary determinants. Because nutrition is strongly related to other behavioural risk factors e.g. smoking, alcohol and physical activity, these risk factors will be also touched upon as well as lifestyle related biological risk factors e.g. total and HDL cholesterol, blood pressure and body mass index.

This chapter deals with the burden of cardiovascular diseases in Europe, secular trends and future developments, biological risk factors, dose-response relations, behavioural risk factors and dietary prevention of cardiovascular diseases.

\section{The burden of cardiovascular diseases in Europe}

Within Europe large differences exist in mortality from coronary heart disease and stroke $^{1}$. Generally mortality differences between populations are analysed at the country level. However, recently the results on spatial analyses of mortality patterns in Europe have become available. The advantage of this type of analysis is that regional variability in mortality patterns can be shown across borders of countries. This may help in identifying factors responsible for this variation. Regional 


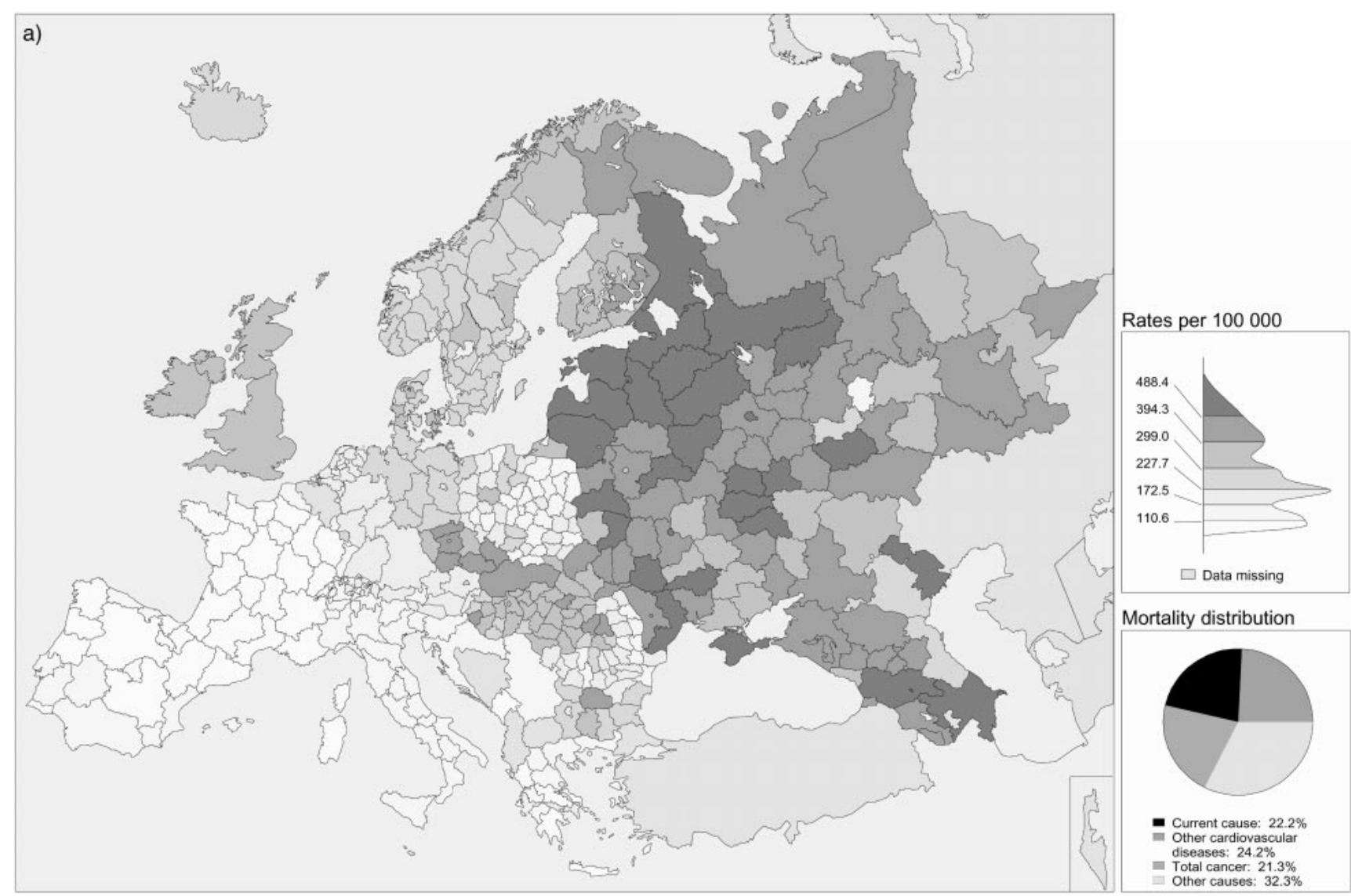




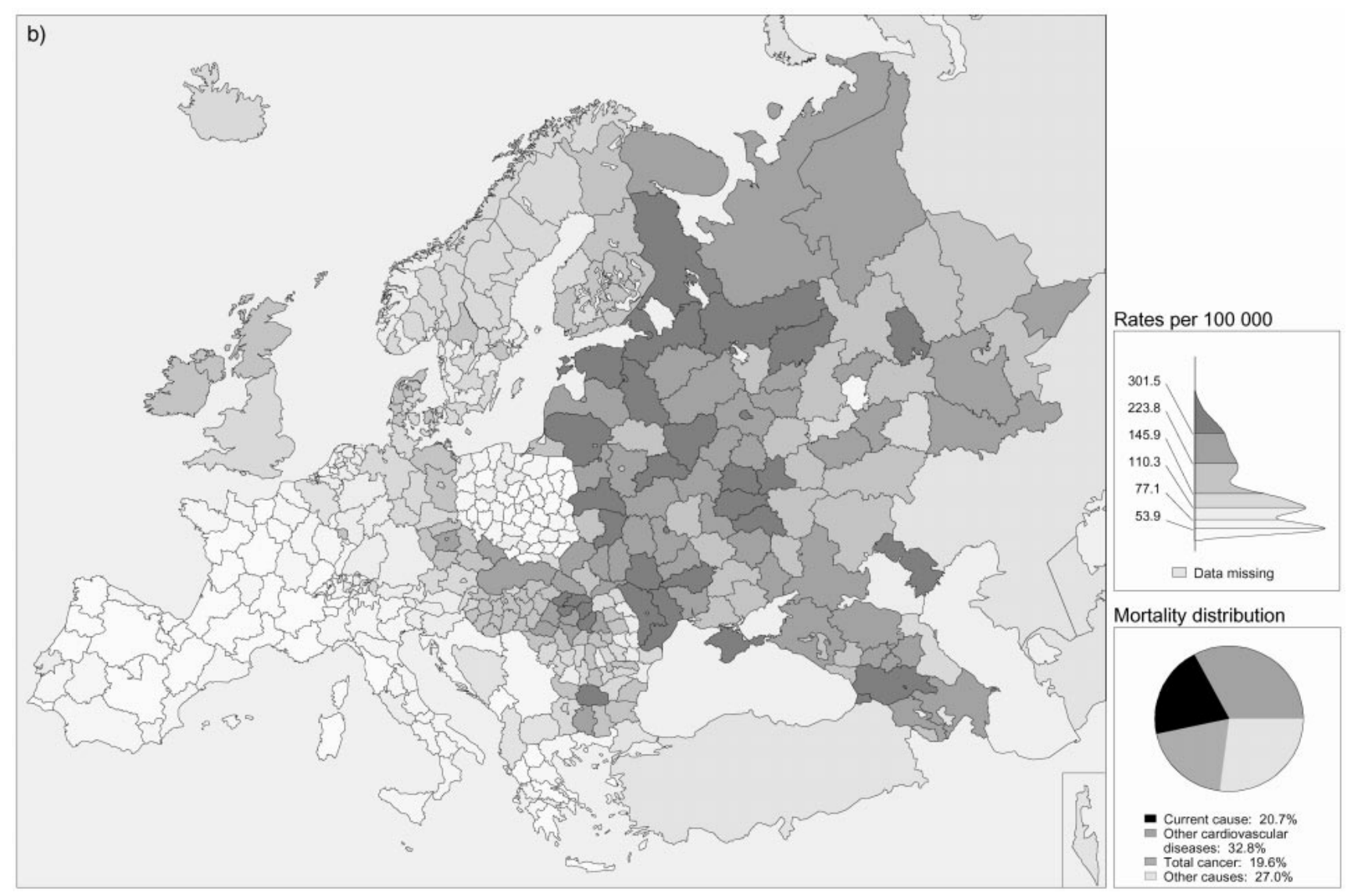

Fig. 1 Age-standardized mortality from coronary heart disease (ICD 410-414) in European regions in 1990-91. All ages. (a) men; (b) women. Reproduced with permission from Sans et al. ${ }^{1}$ 
age-standardised mortality data are available for the years 1990 and 1991. This data was averaged in order to obtain more stable rates. Maps are presented for coronary heart disease and stroke mortality separately.

Coronary heart disease mortality patterns show a clear West- East gradient in both men and women with the highest mortality rates in Eastern Europe (Fig. 1a and b). The ratio between the 90th and the 10th percentile was about 5. The distribution shows that the differences in regional mortality rates within Western Europe are relatively small compared to Eastern Europe. In the United Kingdom, a distinct North-South gradient is noted.

For stroke mortality also a West-East pattern can be observed in both men and women (Fig. 2a and b). There are, however, exceptions. High stroke mortality rates are still observed in Portugal and to a lesser extent in other Mediterranean regions. In contrast to coronary heart disease, the lowest stroke rates were observed in Northern and Western European countries e.g. Sweden, Denmark, The Netherlands and Germany. The ratio between the 90th and 10th percentile was about 5 in both men and women.

In order to get insight into the burden of cardiovascular diseases in Europe it is necessary to get information not only on mortality patterns but also on morbidity patterns. However standardised morbidity rates are much more difficult to obtain than mortality rates. One of the aims of the WHO MONICA project was to obtain valid information on coronary event rates in different populations. The total event rates collected in the MONICA study are a good indicator of comparative incidence ${ }^{2}$. However the best indicator of the burden of cardiovascular diseases would be the number of prevalent cases present in the population. Reliable and comparable estimates of the number of prevalent cases of cardiovascular diseases in Europe are however not available.

Results of the MONICA study showed that 1.0 to 1.5 episodes of hospitalised non-fatal, definite myocardial infarction were registered for every death due to coronary heart disease ${ }^{2}$. The age-standardised annual event rate ranged in men from 915 per 100000 in North Karelia (Finland) to 187 per 100000 in Catalonia (Spain) and in women from 256 per 100000 in Glasgow (UK) to 30 per 100000 in Catalonia (Spain). The event rates of definite non-fatal myocardial infarction in the different MONICA regions correlated well with the coronary heart disease mortality rates based on official death certificates.

To get a reliable estimate of the number of patients with e.g. myocardial infarction is difficult. In a study carried out by a network of GP's in the Netherlands it was shown that the percentage of definite cases of myocardial infarction is only about $50 \%$ of the suspected number of cases ${ }^{3}$. In the Netherlands the current annual number of incident cases of acute myocardial infarction is estimated to be about 25.000 and the number of prevalent cases of coronary heart disease is currently about $150.000^{4}$. This shows that information about the number of prevalent cases is needed in order to get a good estimate of the total burden of a disease in a population.

\section{Secular trends and future developments in cardiovascular diseases}

Mortality trends for coronary heart disease and stroke have been reported by the Task Force of the European Society of Cardiology ${ }^{1}$. For reasons of clarity nine indicator countries were selected to illustrate long-term trends in mortality rates since 1970. The following nine indicator countries represent the large variety in trends; for Central and Eastern Europe, the Russian Federation, the former Czechoslovakia and Hungary, for Western Europe, Denmark and England and Wales; for Northern Europe, Finland; and for Southern Europe; Portugal, Spain and Greece (Fig. 3a and b).

Finland had the highest mortality rate from coronary heart disease of all European countries in 1970, but had intermediate rates 22 years later. Decreasing trends were also observed in Denmark and England and Wales; but there the decline started later than in Finland. Large increases were observed in Central and Eastern European countries, such as Hungary and the former Czechoslovakia. The very high rates in the Russian Federation and the rapid increase since 1990 are noticeable. Portugal, Spain and Greece had very low rates during the whole period. Similar trends were observed in women. However, the increasing trend in Central and Eastern Europe was less pronounced in women compared with men (Fig. 3b).

In the same period substantial differences in stoke mortality were observed between different countries (Fig. $4 \mathrm{a}$ and $\mathrm{b})$. Stroke mortality rates increased until about 1985 in Hungary and the former Czechoslovakia. Thereafter the stroke mortality rates among men declined in Hungary, the former Czechoslovakia and the Russian Federation until about 1990. After 1990 the rates started to increase again in Hungary and the Russian Federation. Consistently decreasing trends were observed in Portugal, Finland, Spain, England and Wales. During the 23-year period persistent low rates were observed in Greece and Denmark. Similar trends were observed in women (Fig. 4b).

In 1990 there were world-wide 6.3 million of deaths due to coronary heart disease and 4.4 million due to stroke on a total of 50.5 million deaths ${ }^{5}$. Murray and Lopez predict that these two diseases will remain the leading causes of death at least till $2020^{6}$. In order to assess the public health importance of different diseases Murray and Lopez used as a standard unit, the disability adjusted life years (DALY) ${ }^{7}$. Cardiovascular diseases contributed $18.5 \%$ to all DALY's in the established market economies of Europe. This means that cardiovascular diseases are not only a major cause of death but are also major contributors to ill health and disability. 
Projections on the future burden of coronary heart disease and stroke are not available for different European countries. Demographic projections have been made for the Netherlands ${ }^{4}$. It is expected that between 1994 and 2015 the number of prevalent cases of coronary heart disease and stroke will increase with 35$45 \%$. If we take $40 \%$ as the best estimate the number of prevalent cases of coronary heart disease will increase from about 150.000 to 210.000 and of stroke patients from about 85.000 to 119.000 . This shows that in spite of decreasing age- standardised mortality rates the number of cardiovascular disease patients will increase substantially in the decades to come. This is the consequence of the ageing of the Dutch population and a decreased case fatality because of successful treatment of cardiovascular patients. Similar trends are observed in other Western European countries. Besides the already dramatic situation in relation to cardiovascular diseases in Eastern Europe it is expected that also in Western European countries the number of cardiovascular patients will increase. It may therefore be concluded that we will be confronted with a large increase in the number of cardiovascular patients in the years to come.

\section{Biological risk factors for cardiovascular diseases}

Classic epidemiologic studies have shown that serum cholesterol and blood pressure are important risk factors for coronary heart disease. Blood pressure is also a major determinant of stroke. In observational epidemiology serum cholesterol is not related to stroke. However, if information on the type of stroke is available, haemorragic stroke seems to be inversely related with serum cholesterol and thrombotic stroke positively.

Cholesterol is transported in different lipoprotein fractions. The Low Density Lipoprotein (LDL) fraction is rich in cholesterol. Experimental research has shown that oxidised LDL (oxLDL) is a major determinant of atherosclerosis $^{8}$. Because of the strong correlation between LDL cholesterol and total cholesterol the later can be viewed as an indicator of LDL cholesterol.

Of the other lipoprotein fractions the High Density Lipoproteins (HDL) were shown to be inversely related with coronary heart disease occurrence. Experimental research has shown that HDL is involved in the reverse transport of cholesterol from the peripheral tissues to the liver. In the liver cholesterol can be metabolised to bile acids and be excreted. Based on the results of both epidemiologic and experimental research it can be concluded that the total/HDL cholesterol ratio is the best predictor of the effect of lipid metabolism on coronary heart disease risk 9 .

Blood pressure has been identified as one of the major risk factors for both coronary heart disease and stroke. Observational and experimental studies have shown that diastolic blood pressure is a strong predictor of both coronary heart disease and stroke $\mathrm{e}^{10,11}$. Casually measured systolic blood pressure is stronger related to cardiovascular endpoints than diastolic blood pressure ${ }^{12}$. An explanation for this difference in predictive power could be less measurement error in the determination of systolic compared with diastolic blood pressure.

Body fat has been viewed as a risk factor for coronary heart disease for a long time. Generally Body Mass Index $\left(\mathrm{BMI}=\right.$ weight $/$ height $\left.^{2}\right)$ is used as an indicator of body fat in epidemiologic studies. However the results of epidemiologic studies on the relation between BMI and coronary heart disease are not unequivocal. The strength of the association seems to decrease with age. However, in both men and women with an average age of 40 years the risk on coronary heart disease mortality is positively associated with BMI from a BMI of 18.5 and higher ${ }^{13}$. This association is strongest in non-smokers. There is no convincing evidence that BMI is a risk factor for stroke.

It can be concluded that in middle age total cholesterol, HDL cholesterol, blood pressure and BMI are important risk factors for coronary heart disease. For these risk factors blood pressure is the only one that is convincingly related with stroke. Since the beginning of the epidemiology of cardiovascular diseases information has been collected on total cholesterol, blood pressure and BMI. The levels and the trends in these risk factors in Europe can therefore be described.

Standardised information on these biological risk factors has been collected in the Seven Countries and the MONICA Study ${ }^{2,14-16}$. The Seven Countries Study started in 1958 and the MONICA Study in the 1980s. MONICA data are used to describe the current situation in Europe and the short-term trends in biological risk factors. The Seven Countries Study and the MONICA data are used to describe the long-term trends in biological risk factors in middle-aged men.

Around 1995 mean serum total cholesterol levels were the highest in Central Europe and lowest in Southern Europe (e.g. $6.4 \mathrm{mmol} / \mathrm{l}$ in Novi Sad, Serbia and $5.6 \mathrm{mmol} / \mathrm{l}$ in Catalonia, Spain, Table 1). High total cholesterol levels $(\geq 7.8 \mathrm{mmol} / \mathrm{l}$ ) varied from $13 \%$ in Novi Sad to 3\% in Catalonia.

Mean systolic blood pressure levels did not show a clear North-South gradient. High levels were observed in both Northern (North Karelia, Finland) and Southern (Friuli, Italy) Europe. The same holds for low levels that were also observed in both in Northern (Iceland) and in Southern (Catalonia, Spain) Europe. Large variations were present with respect to the prevalence of hypertension (systolic $\mathrm{BP} \geq 160 \mathrm{mmHg}$ and/or diastolic $\mathrm{BP} \geq 95 \mathrm{mmHg}$ and/or antihypertensive medication). This varied between 36\% in North Karelia and 10\% in Catalonia.

Body Mass Index did not vary much between the different populations. Both the highest and the lowest average values were found in Northern Europe e.g. in North Karelia $\left(27.5 \mathrm{~kg} / \mathrm{m}^{2}\right)$ and Glostrup, Denmark 


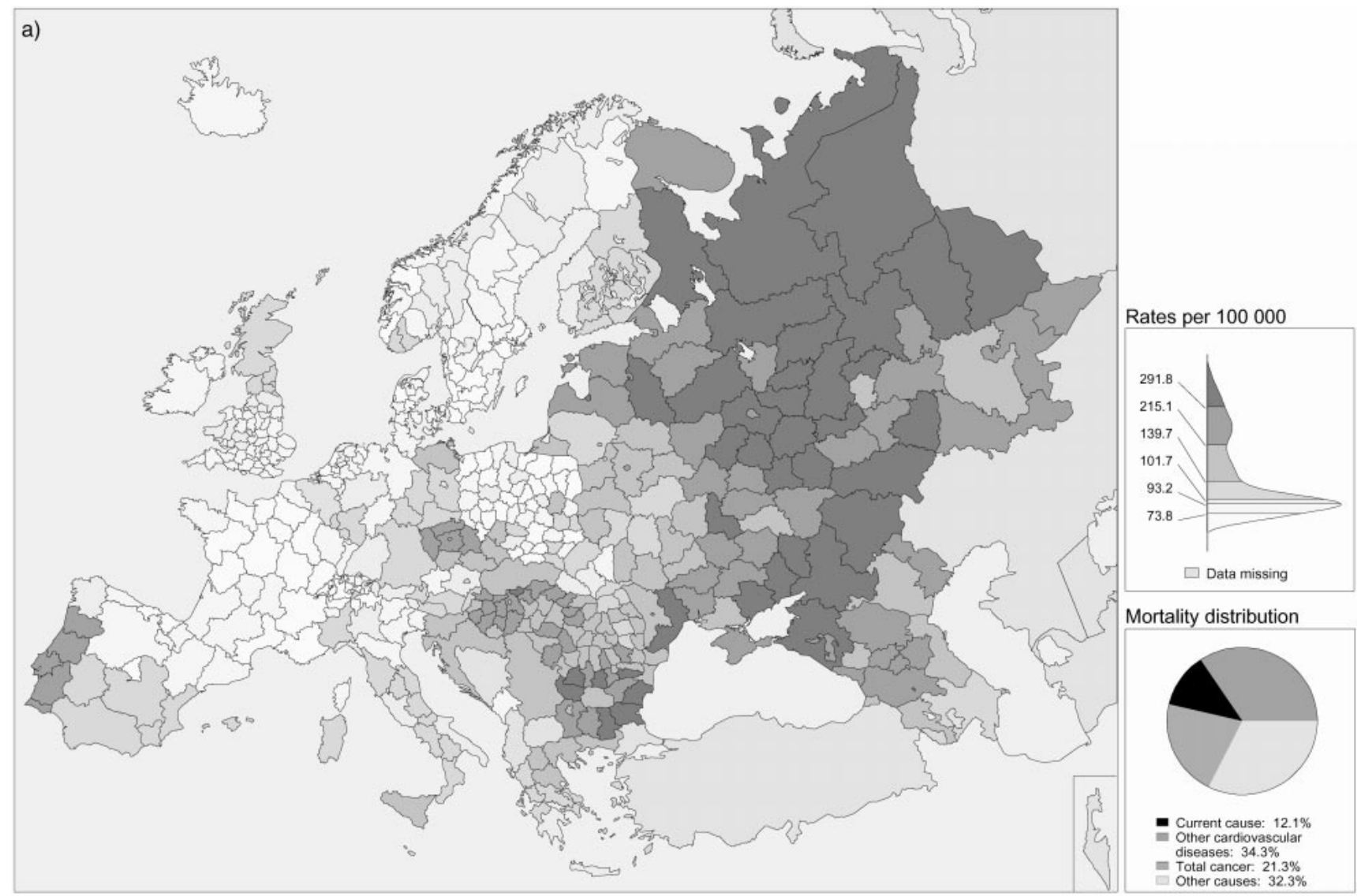




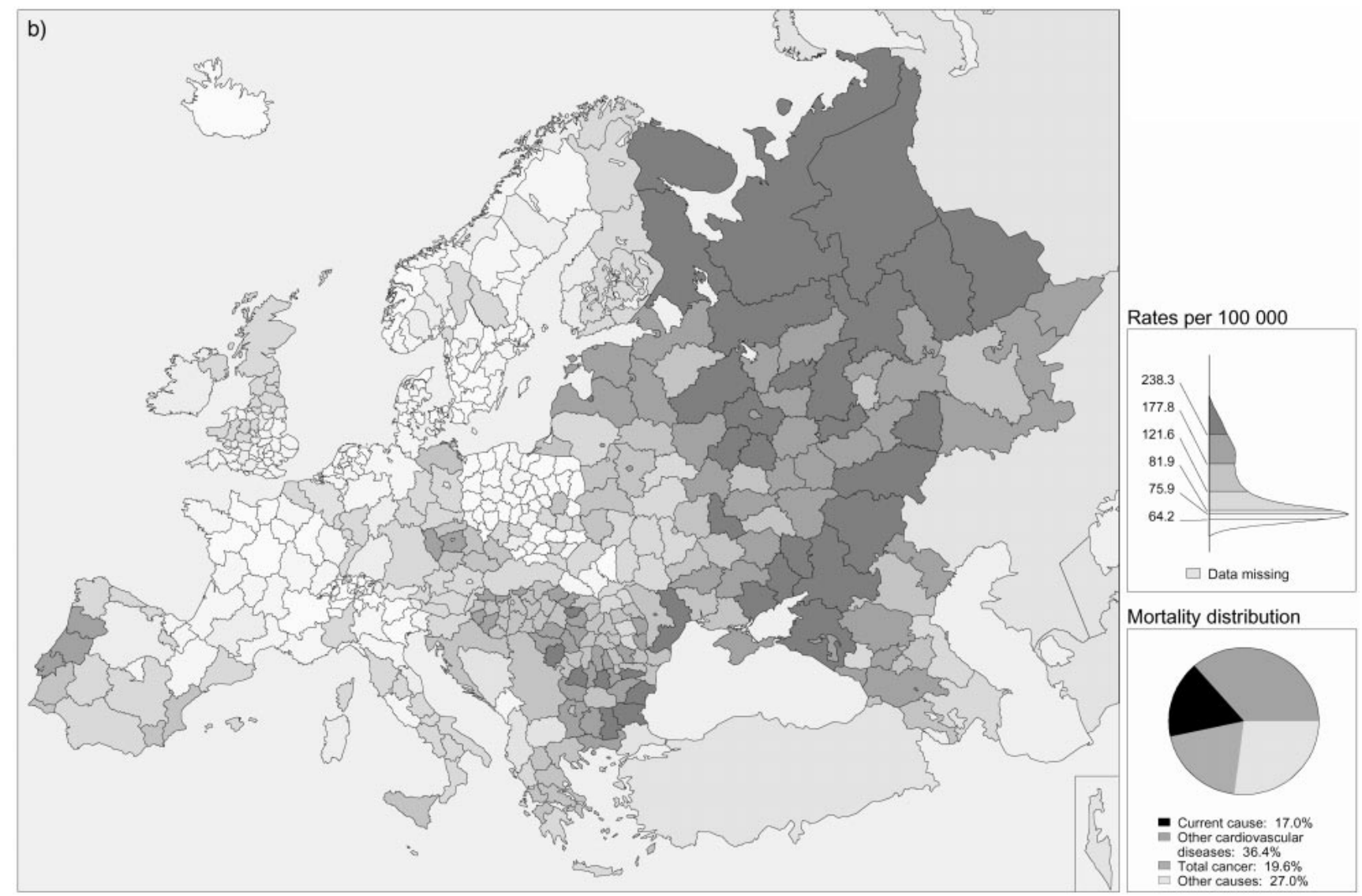

Fig. 2 Age-standardized mortality from stroke (ICD 430-438) in European regions in 1990-91. All ages. (a) men; (b) women. Reproduced with permission from Sans et al. ${ }^{1}$ 

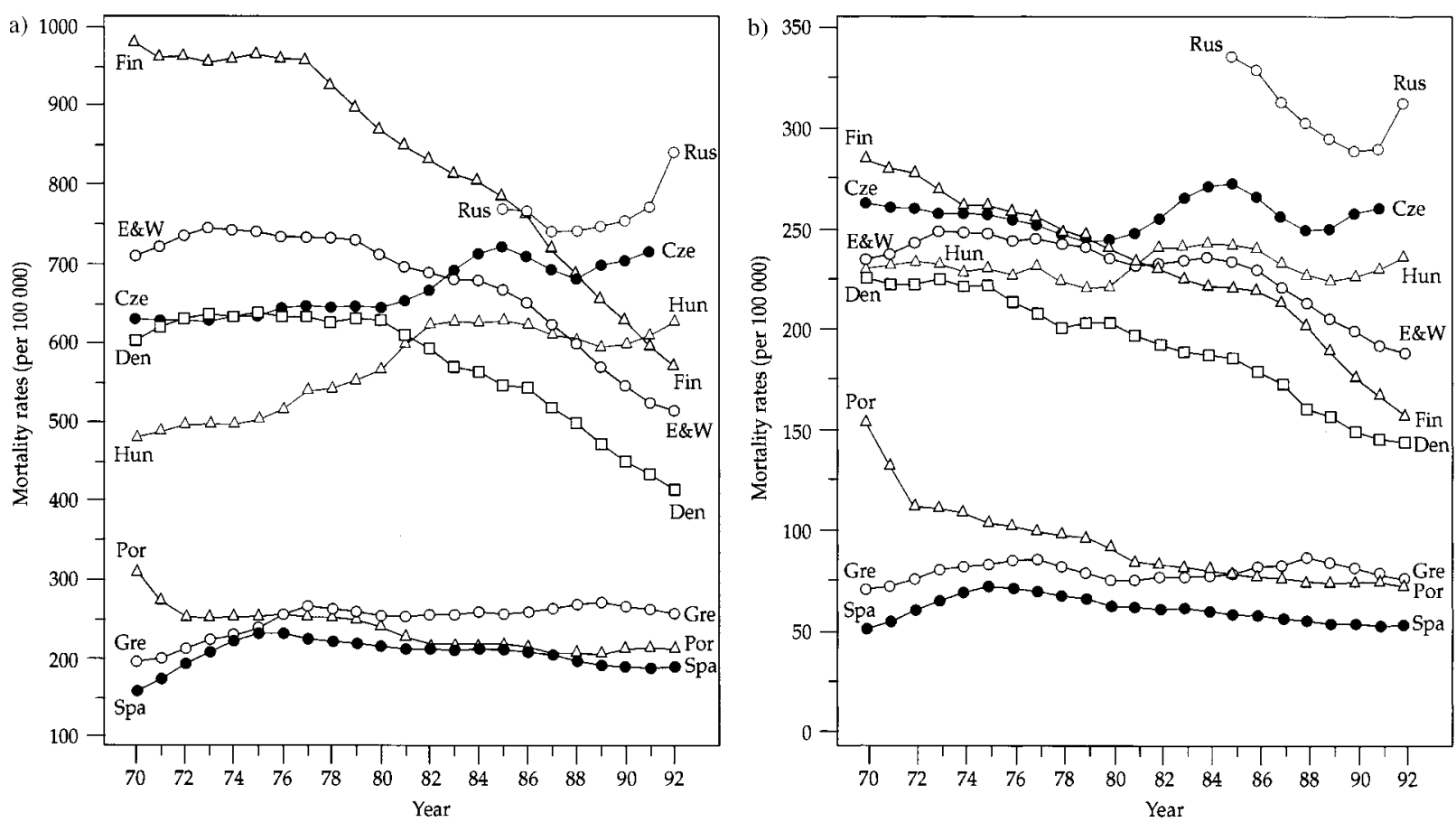

Fig. 3 Time-trends in mortality from coronary heart disease in selected countries. 1970-92. Age 45-74 years. (a) men; (b) women. Reproduced with permission from Sans et al. ${ }^{1}$

$\left(26.0 \mathrm{~kg} / \mathrm{m}^{2}\right.$ ). The prevalence of obesity (BMI $\geq 30 \mathrm{~kg} /$ $\mathrm{m}^{2}$ ) varied between $23 \%$ in North Karelia and 13\% in Glostrup.

Information on the trends in biological risk factors in the period 1985-1995 was recently published by the MONICA investigators ${ }^{16}$. For serum total cholesterol an

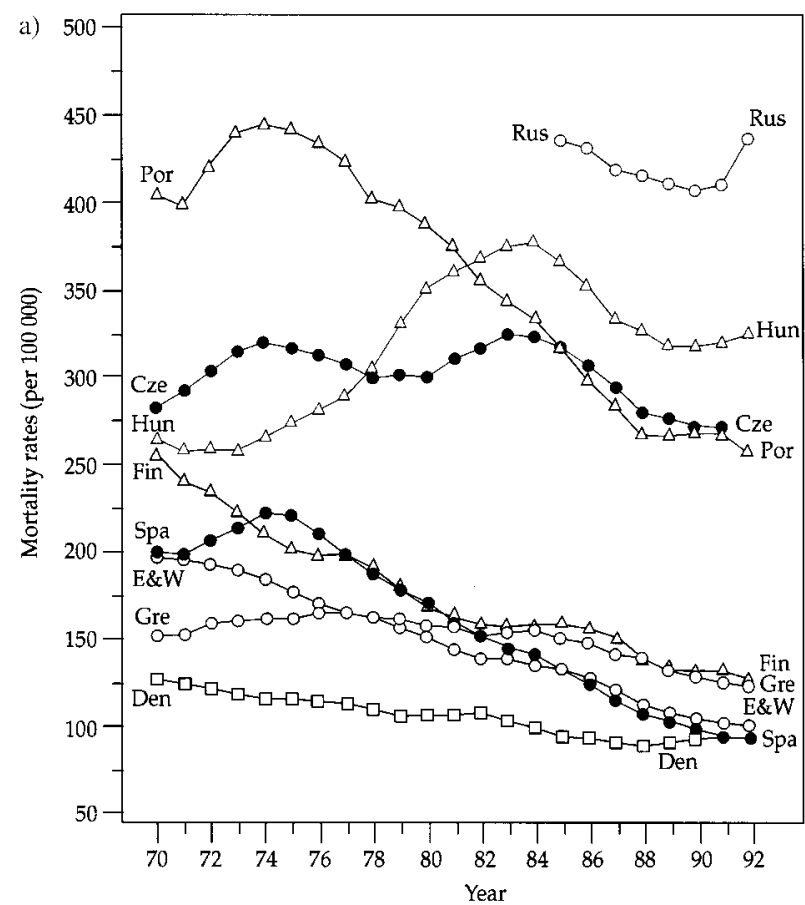

average decrease of about $0.4 \mathrm{mmol} / \mathrm{l}$ during 10 years was observed in Finland (Table 2). A smaller decrease was observed in most Western European countries. The average changes in systolic blood pressure varied during the 10 year period from a $13.5 \mathrm{mmHg}$ decrease in Warsaw (Poland) to a $5 \mathrm{mmHg}$ increase in Novi Sad (Serbia). With

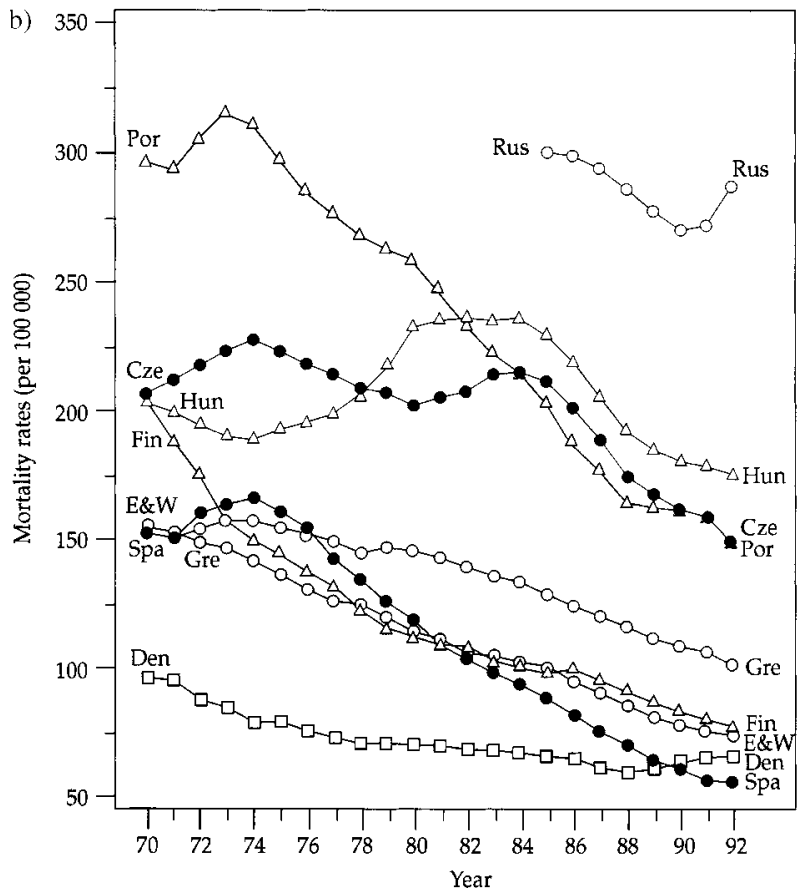

Fig. 4 Time-trends in age-standardized mortality from stroke in selected countries. 1970-92. Age 45-74. (a) men; (b) women. Reproduced with permission from Sans et al. ${ }^{1}$ 
Table 1 Mean levels of biological risk factors for coronary heart disease in men aged 35-64 years in European populations around 1995 (The WHO MONICA Project ${ }^{16}$ )

\begin{tabular}{|c|c|c|c|c|c|c|}
\hline Population & $\begin{array}{l}\text { Cholesterol } \\
(\mathrm{mmol} / \mathrm{l})\end{array}$ & $\begin{array}{c}\text { Chol. } \geq 7.8 \mathrm{mmol} / / \mathrm{l} \\
(\%)\end{array}$ & $\begin{array}{l}\text { Syst. BP. } \\
(\mathrm{mmHg})\end{array}$ & $\begin{array}{l}\text { Hypertension* } \\
(\%)\end{array}$ & $\begin{array}{c}\mathrm{BMI} \\
\left(\mathrm{kg} / \mathrm{m}^{2}\right)\end{array}$ & $\begin{array}{c}\text { Obesity } \\
\text { BMI } \geq 30 \mathrm{~kg} / \mathrm{m}^{2}(\%)\end{array}$ \\
\hline \multicolumn{7}{|l|}{ Northern Europe } \\
\hline N. Karelia (SF) & 6.0 & 7 & 142 & 36 & 27.5 & 23 \\
\hline Turku/Loimaa (SF) & 5.9 & 4 & 139 & 33 & 27.1 & 22 \\
\hline Iceland & 6.2 & 10 & 125 & 18 & 26.8 & 16 \\
\hline Glostrup (D) & 6.0 & 5 & 126 & 21 & 26.0 & 13 \\
\hline \multicolumn{7}{|l|}{ Western Europe } \\
\hline Belfast (NI) & 5.9 & 6 & 135 & 27 & 26.3 & 14 \\
\hline Glasgow (SC) & 6.1 & 6 & 133 & 26 & 26.8 & 23 \\
\hline Ghent (B) & 6.0 & 6 & 129 & 19 & 26.4 & 13 \\
\hline Ausburg urban (G) & 6.2 & 10 & 137 & 26 & 27.1 & 17 \\
\hline \multicolumn{7}{|c|}{ Central and Eastern Europe } \\
\hline Warsaw $(P)$ & 5.7 & 3 & 132 & 29 & 27.1 & 22 \\
\hline Kaunas (L) & 6.0 & 7 & 137 & 31 & 27.1 & 20 \\
\hline Novi Sad (SE) & 6.4 & 13 & 136 & 32 & 27.3 & 20 \\
\hline \multicolumn{7}{|l|}{ Southern Europe } \\
\hline Friuli (I) & 5.9 & 5 & 140 & 27 & 26.9 & 17 \\
\hline Brianza (I) & 5.9 & 6 & 131 & 25 & 26.4 & 14 \\
\hline Catalonia (SP) & 5.6 & 3 & 121 & 10 & 26.7 & 16 \\
\hline
\end{tabular}

* Hypertension is defined as systolic $\mathrm{BP} \geq 160 \mathrm{mmHg}$ and/or diastolic $\mathrm{BP} \geq 95 \mathrm{Hg}$ and/or antihypertensive medication.

the exception of Kaunas (Lithuania) an increase in average BMI was observed. The largest increase between 1985 and 1995 was observed in Ghent (Belgium) and amounted to $1.4 \mathrm{~kg} / \mathrm{m}^{2}$. This is equivalent to an average increase in body weight of about $4 \mathrm{~kg}$ during a 10-year period.

Information on the long-term trends of biological risk factors in middle-aged men could be obtained by comparing data from the baseline survey of the Seven Countries Study carried out around 1960 and the MONICA surveys carried out in the period 1985-1995. Some remarkable trends are noted. During this 35 year period mean total cholesterol levels in Finland did decrease with $0.7 \mathrm{mmol} / \mathrm{l}$ (Table 3). No change was found comparing data from the Netherlands and Belgium. An increase in mean total cholesterol level was observed in Italy and Serbia. In Serbia the average serum total cholesterol level increased by more than $2 \mathrm{mmol} / \mathrm{l}$. Similar longitudinal changes were observed in the Finnish, Dutch, Italian and Serbian cohorts of the Seven Countries Study ${ }^{17,18}$.

Table 2 Mean levels and annual average change in the period 1985-1995 of biological risk factors for coronary heart disease in men aged $35-64$ years in European populations (The WHO MONICA project ${ }^{16}$ )

\begin{tabular}{|c|c|c|c|c|c|c|}
\hline Population & $\begin{array}{c}\text { Tot chol } \\
\text { (mmol/l/) Mean } \\
\text { for } 1995 \text { survey }\end{array}$ & $\begin{array}{l}\text { Average annual } \\
\text { change }\end{array}$ & $\begin{array}{c}\text { Syst. BP } \\
(\mathrm{mmHg}) \text { Mean } \\
\text { for } 1995 \text { survey }\end{array}$ & $\begin{array}{l}\text { Average annual } \\
\text { change }\end{array}$ & $\begin{array}{l}\text { BMI }\left(\mathrm{kg} / \mathrm{m}^{2}\right) \\
\text { Mean for } 1995 \\
\text { survey }\end{array}$ & $\begin{array}{c}\text { Average annual } \\
\text { change }\end{array}$ \\
\hline \multicolumn{7}{|l|}{ Northern Europe } \\
\hline N. Karelia (SF) & 6.0 & -0.034 & 142 & -0.06 & 27.5 & 0.06 \\
\hline Turku/Loimaa (SF) & 5.9 & -0.045 & 139 & -0.52 & 27.1 & 0.09 \\
\hline Iceland & 6.2 & 0.015 & 125 & 0.08 & 26.8 & 0.09 \\
\hline Glostrup (D) & 6.0 & 0.001 & 126 & -0.08 & 26.0 & 0.05 \\
\hline \multicolumn{7}{|l|}{ Western Europe } \\
\hline Belfast (NI) & 5.9 & -0.012 & 135 & 0.12 & 26.3 & 0.06 \\
\hline Glasgow (SC) & 6.1 & -0.011 & 133 & -0.70 & 26.8 & 0.12 \\
\hline Ghent (B) & 6.0 & -0.026 & 129 & 0.37 & 26.4 & 0.14 \\
\hline Ausburg urban $(\mathrm{G})$ & 6.2 & -0.013 & 137 & 0.24 & 27.1 & 0.03 \\
\hline \multicolumn{7}{|c|}{ Central and Eastern Europe } \\
\hline Warsaw $(\mathrm{P})$ & 5.7 & 0.020 & 132 & -1.35 & 27.1 & 0.03 \\
\hline Kaunas (L) & 6.0 & -0.016 & 137 & 0.16 & 27.1 & -0.07 \\
\hline Novi Sad (SE) & 6.4 & 0.089 & 136 & 0.48 & 27.3 & 0.07 \\
\hline \multicolumn{7}{|l|}{ Southern Europe } \\
\hline Friuli (I) & 5.9 & -0.042 & 140 & -0.19 & 26.9 & 0.06 \\
\hline Brianza (I) & 5.9 & 0.037 & 131 & -0.71 & 26.4 & 0.10 \\
\hline Catalonia (SP) & 5.6 & -0.023 & 121 & -0.50 & 26.7 & 0.09 \\
\hline
\end{tabular}


Table 3 Trends in mean levels of biological risk factors in men with an average age of 50 years in the period 1960-1995 in European populations ${ }^{14-16, *}$

\begin{tabular}{|c|c|c|c|c|c|c|c|c|c|}
\hline \multirow[b]{2}{*}{ Place } & \multicolumn{3}{|c|}{ Cholesterol $(\mathrm{mmol} / \mathrm{l})$} & \multicolumn{3}{|c|}{ Syst.BP (mmHg) } & \multicolumn{3}{|c|}{ BMI $\left(\mathrm{kg} / \mathrm{m}^{2}\right)$} \\
\hline & 1960 & 1985 & 1995 & 1960 & 1985 & 1995 & 1960 & 1985 & 1995 \\
\hline North Karelia (SF) & 6.8 & 6.4 & 6.0 & 146 & 144 & 142 & 23.0 & 26.9 & 27.5 \\
\hline Turku/Loimaa (SF) & 6.5 & 6.2 & 5.9 & 138 & 143 & 139 & 23.7 & 26.9 & 27.1 \\
\hline Zutphen (NL) & 6.0 & & & 141 & & & 24.0 & & \\
\hline Ghent $(B)$ & & 6.1 & 6.0 & & 127 & 129 & & 26.1 & 26.4 \\
\hline Zrenjanin (SE) & 4.3 & & & 130 & & & 24.7 & & \\
\hline Novi Sad (SE) & & - & 6.4 & & 135 & 136 & & 26.7 & 27.3 \\
\hline Crevalcore (I) & 5.1 & & & 145 & & & 25.6 & & \\
\hline Friuli (I) & & 6.3 & 5.9 & & 142 & 140 & & 26.6 & 26.9 \\
\hline Montegiorgio (I) & 5.1 & & & 135 & & & 23.9 & & \\
\hline Brianza (I) & & 5.6 & 5.9 & & 137 & 131 & & 25.7 & 26.4 \\
\hline
\end{tabular}

* The 1960 data are the baseline data of the Seven Countries Study. The 1985 and 1995 data are of the WHO MONICA project.

The trend in mean systolic blood pressure values is less clear. A decrease of about $5 \mathrm{mmHg}$ in systolic blood pressure was observed in North Karelia (Finland) and in Italy. A large decrease of $15 \mathrm{mmHg}$ in mean systolic blood pressure was observed when data collected in middleaged men in the Netherlands around 1960 were compared with those of Belgian counterparts examined 25 years later. Also in the Netherlands a substantial decrease in systolic blood pressure was noted when middle-aged men examined around 1960 were compared with those examined between 1987 and 1991 (141 vs $126 \mathrm{mmHg}$ ). These results suggest that in the Netherlands a substantial decrease in blood pressure took place between 1960 and 1990. In contrast a $6 \mathrm{mmHg}$ increase was observed in Serbia. This is compatible with the longitudinal changes observed in the Serbian cohorts of the Seven Countries Study ${ }^{18}$.

A consistent increase in mean BMI was observed in populations from different parts of Europe. The average increase varied from 1.3 to $4.5 \mathrm{~kg} / \mathrm{m}^{2}$ and corresponds with an average increase in body weight from $4-14 \mathrm{~kg}$ in a 35 year period. This seems to be an universal phenomenon in both developed and developing countries. A global epidemic is developing because of a high prevalence of physical inactivity and the consumption of energy dense diets.

\section{Dose-response relationship}

The exact nature of the relations between biological risk factors and cardiovascular diseases is difficult to establish. Biological risk factors can not be measured without error. Serum cholesterol can nowadays be measured accurately (coefficient of variation $<3 \%$ ) in certified laboratories. Besides measurement error there is also a substantial intra- individual variation in biological risk factors. The intra- individual variation in serum cholesterol on a constant diet is about $0.5 \mathrm{mmol} / 1^{19}$. Both measurement error and intra-individual variation should be taken into account in judging associations between biological risk factors and coronary heart disease mortality.

The correlation between yearly measurements of serum cholesterol is about 0.8 and for systolic blood pressure about 0.7 . The correlation between the initial measurements and the measurements at 26 years of follow-up was in the Framingham Study 0.46 for cholesterol and 0.31 for systolic blood pressure ${ }^{20}$. This information can be used to calculate the so-called regression dilution factor. By adjusting for regression dilution bias the real strength of an association between a biological risk factor and disease occurrence can be calculated.

We calculated regression dilution factors for 6 populations in the Seven Countries Study ${ }^{12,21}$. We found that without correcting for regression dilution the strength of the association for serum cholesterol and systolic blood pressure in relation to long-term coronary heart disease mortality was underestimated with $45 \%$ and $60 \%$ resp. This shows the need of repeat measures of biological risk factors in order to make proper estimates of relations between biological risk factors and disease endpoints.

All epidemiologic studies showed that the associations between serum cholesterol and coronary heart disease and between systolic blood pressure and coronary heart disease were graded. In the Seven Countries Study we tested whether the risk ratios for coronary heart disease mortality were different in relation to a certain increase in serum cholesterol and systolic blood pressure in different cultures. We found that for both serum cholesterol and systolic blood pressure the risk ratios for coronary heart disease mortality did not differ between cultures ${ }^{12,21}$. However substantial differences were found in absolute risk in different cultures. The absolute risk for long-term coronary heart disease mortality was 5 times higher in Northern Europe (Finland and the Netherlands) compared with Mediterranean Southern Europe (Italy and Greece) at a cholesterol level of $5.2 \mathrm{mmol} / \mathrm{l}$. The same 
holds for systolic blood pressure. At a level of $140 \mathrm{mmHg}$ the absolute risk is about 3 times higher in Northern Europe compared to Mediterranean Southern Europe.

These results have great implications from a public health point of view. Prevention and treatment of a certain serum cholesterol or blood pressure level is associated with a greater health effect in Northern Europe than in Southern Europe, assuming a similar reduction in risk factors in these regions. The formulation of different target levels for serum cholesterol and blood pressure lowering in Northern and Southern Europe should therefore be considered.

Another point of consideration is that serum cholesterol or blood pressure lowering alone for persons at high risk is not enough. A global risk score based on the major coronary heart disease risk factors should be calculated as advised by the European Society of Cardiology ${ }^{22}$. Those at high risk should lower serum cholesterol and blood pressure below the target values. However, in Northern Europe that is not enough. Improvement of the diet e.g. a low intake of saturated and trans fatty acids and an adequate intake of poly-unsaturated fatty acids and antioxidants, may be necessary in order to achieve a risk as low as in the Mediterranean countries.

\section{Behavioural risk factors of cardiovascular diseases}

Because of the large variation in the mortality from coronary heart disease and stroke it is likely that behavioural risk factors play an important role in the etiology of these diseases. The emphasis will be on dietary determinants of coronary heart disease because much less is known about the dietary determinants of stroke. Different behavioural risk factors are closely intertwined. Therefore besides diet also attention will be paid to alcohol, smoking and physical activity. Finally attention will be paid to the interaction between behavioural risk factors and genetic factors.

\section{Fatty acids and coronary beart disease}

In 1952 Keys hypothesised that serum cholesterol is a major determinant of coronary heart disease ${ }^{23}$. At that time it was thought that dietary cholesterol and total fat were the major determinants of serum cholesterol. Later on it became clear that not dietary cholesterol and total fat but individual fatty acids especially saturated fatty acids with 12-16 carbon atoms were the most important determinants of serum cholesterol. These fatty acids have a strong cholesterol elevating effect and were at the population level strongly related to long-term coronary heart disease mortality ${ }^{24}$.

In prospective cohort studies generally weaker associations are observed between the intake of saturated fat, serum cholesterol and coronary heart disease than expected from experimental studies ${ }^{25}$. This effect may be real but can also be due to the inaccurate measurement of saturated fat intake in observational studies. Saturated fat is present in a lot of foods and in complex dishes like gravy. This may be a reason why an accurate estimate of the intake of saturated fat is difficult to obtain in everyday life.

During the hardening process of polyunsaturated fatty acid rich oils for margarine production so-called trans fatty acids are formed. Controlled dietary experiments have shown that especially the trans fatty acid elaidic acid has a total and LDL cholesterol elevating effect and a HDL cholesterol lowering effect ${ }^{26}$. The HDL cholesterol lowering effect of elaidic acid seems to be confined to high intake levels. In the Seven Countries Study the population intake of elaidic acid was significantly related to long-term coronary heart disease mortality ${ }^{24}$. Also at the individual level the intake of trans fatty acids was positively associated with the occurrence of coronary heart disease as was shown in the Nurses Health Study ${ }^{27}$.

Cis mono-unsaturated fatty acids present in e.g. olive oil and margarine's, lower total and LDL cholesterol compared with saturated fatty acids and do not, in contrast to carbohydrates, lower HDL cholesterol. This is the reason that some scientists prefer these monounsaturated fatty acids above carbohydrates for total and LDL cholesterol lowering ${ }^{28}$. However, there is no observational epidemiologic and clinical trial evidence that a diet low in saturated fat and high in cis monounsaturated fat compared to a diet low in saturated fat and high in carbohydrates and dietary fiber is superior in relation to the occurrence of coronary heart disease. More evidence is needed before definite statements on this issue can be made.

Polyunsaturated fatty acids consist of two parent compounds: linoleic acid, a fatty acid of the N-6 family with 18 carbon atoms and two double bonds and $\alpha$ linolenic acid, a fatty acid of the N-3 family with 18 carbon atoms and 3 double bonds. These fatty acids have different metabolic effects. Linoleic acid (LA) can be elongated to arachidonic acid (AA), a fatty acid with 20 carbon atoms and 4 double bonds. $\alpha$-Linolenic acid can be elongated to either eicosapentaenoic acid (EPA), a fatty acid with 20 carbon atoms and 5 double bonds or docosahexaenoic acid (DHA), a fatty acid with 22 carbon atoms and 6 double bonds. The fatty acids with 20 carbon atoms, AA and EPA, play an important role in prostaglandin metabolism and may influence the thrombotic process.

In Western European populations with an average intake of linoleic acid of more than $4 \%$ of energy no association between linoleic acid intake and coronary heart disease is observed. In earlier days an inverse association between linoleic acid and coronary heart disease was observed in countries with a low intake of linoleic acid e.g. Finland and Scotland.

In prospective cohort studies evidence is accumulating that the intake of $\alpha$-linolenic acid is inversely related with 
coronary heart disease ${ }^{29}$. However, whether this effect is independent of other unsaturated fatty acids e.g. linoleic acid, is difficult to establish because different unsaturated fatty acids are present in the same foods e.g. soybean oil. However, the hypothesis of a protective effect of $\alpha$ linolenic acid in relation to coronary heart disease is supported by the results of the Lyon trial. In this intervention study a Mediterranean diet enriched with $\alpha$-linolenic acid was strongly protective in relation to coronary heart disease ${ }^{30}$. However, more information is needed before definite statements can be made about the possible protective effect of $\alpha$-linolenic acid.

Fish is an important source of the N-3 fatty acids EPA and DHA. We found in two prospective studies carried out in the Netherlands that a small amount of fish protects against coronary heart disease mortality ${ }^{31,32}$. This association was also observed in several other prospective studies but not in all ${ }^{33}$. The association was found in cultures with a low fish intake especially if persons who did not consume fish were compared with those who consumed fish once a week. The association also depends on the endpoint. Associations are observed for hard endpoints e.g. coronary mortality or cardiac arrest but not for softer endpoints e.g. non-fatal coronary heart disease. There is now also evidence from two intervention trials that cardiac patients who eat at least twice a week fatty fish or take a supplement of 1 gram of $\mathrm{N}-3$ polyunsaturated fatty acids per day are protected against coronary heart disease mortality ${ }^{34,35}$. It can be concluded that consumption of fish once or twice a week is protective in relation to coronary heart disease mortality.

\section{Antioxidants and coronary beart disease}

Research on antioxidants has traditionally been focused on (pro-) vitamins with antioxidant properties e.g. tocopherols (vitamin E), carotenoids ( $\beta$-carotene) and vitamin $\mathrm{C}$. Besides these so-called nutritive antioxidants there are also non-nutritive antioxidants. Non-nutritive substances are compounds in foods without nutritional value. Recently it became clear that especially plant foods contain numerous compounds with strong antioxidant properties e.g. polyphenols. Important examples are flavonols e.g. quercetin that is present in onions and apples and catechins e.g. epigallocatechin that is present in tea. The associations between (non)-nutritive antioxidants and coronary heart disease will be summarised.

In case-control studies convincing associations between the vitamin $\mathrm{E}$ concentration in blood or adipose tissue and coronary heart disease have not been shown. In five prospective studies inverse associations were observed between vitamin $\mathrm{E}$ intake and coronary heart disease risk ${ }^{36-40}$. However, in three studies this association was noted for supplement users and in two studies for the vitamin $\mathrm{E}$ content in the diet. In three secondary prevention trials the hypothesis was tested whether vitamin E supplementation could prevent re-infarction and mortality. In one trial vitamin E supplementation prevented re-infarctions but not mortality ${ }^{41}$. In the other two trials no effect of vitamin E supplementation was observed $^{35,42}$. It can be concluded that the evidence for a relation between vitamin $\mathrm{E}$ and coronary heart disease is not convincing.

Generally no association was observed between $\beta$ carotene and coronary heart disease in observational studies $^{38,39,40,43}$. One study found a protective effect of $\beta$ carotene on coronary heart disease in smokers ${ }^{37}$. In three large intervention trials mainly carried out in smokers no association was observed between supplementation of $\beta$ carotene and cardiovascular mortality ${ }^{44-46}$. In prospective studies no association was observed between vitamin $\mathrm{C}$ intake and coronary heart disease. Controlled trials on the association between vitamin $\mathrm{C}$ intake and coronary heart disease have not been carried out. It can be concluded that there is no convincing evidence for relations between either $\beta$-carotene or vitamin $\mathrm{C}$ and coronary heart disease.

In 1993 we published a paper showing an inverse relation between the intake of flavonols and the 5-year mortality from coronary heart disease in the Zutphen Elderly Study ${ }^{47}$. This association was also present when the follow-up period was extended to 10 years. The association between flavonol intake and coronary heart disease was also studied in three prospective studies carried out in Finland, USA and Wales ${ }^{48-50}$. One found an inverse association and two did not find a relation. It can be concluded that the association between flavonol intake and coronary heart disease is promising but more data are needed before definite conclusions can be drawn.

In the Seven Countries Study the association between the intake of different antioxidants and long-term coronary heart disease mortality was studied at the population level ${ }^{51,52}$. The average population intake of vitamin $\mathrm{E}, \beta$-carotene and vitamin $\mathrm{C}$ was not related to 25 year coronary heart disease mortality rates ${ }^{51}$. However, the average population intake of flavonols was inversely related with 25-year coronary heart disease mortality rates $^{52}$. These results are generally spoken in accord with those of case-control and cohort studies.

\section{Diet and blood pressure}

Blood pressure is an important determinant of different cardiovascular diseases e.g. coronary heart disease, stroke and kidney failure. In Western societies an increase in blood pressure with age is noted ${ }^{53}$. This increase in blood pressure is an important determinant of the occurrence in cardiovascular diseases. Therefore, there is a great interest in preventing the increase in blood pressure with age.

In so-called primitive societies as the Yanomamo Indians in Brazil, no increase in blood pressure with age is noted ${ }^{53}$. This is generally ascribed to the low sodium intake of these populations. However they have also a high intake of plant foods, are physically active, drink less alcohol and are leaner than their Western counterparts. 
This suggests that factors other than a low sodium intake may explain these low blood pressure levels. This also holds for the so-called Kempner rice-fruit diet that is used in the treatments of hypertension since the 1940s. Apart from being low in sodium, this diet is also high in potassium, low in energy and alcohol.

Recently a paradigm shift is occurring in relation to diet and blood pressure. Recent meta-analysis and trials show only a modest effect of sodium reduction in relation to blood pressure lowering ${ }^{54}$. At the same time the DASH trial showed that with dietary changes a 5-6 mmHg lower systolic blood pressure in subjects with normal blood pressure and of $11-12 \mathrm{mmHg}$ in persons with mild hypertension could be obtained ${ }^{55}$. The diet used in this trial was rich in low-fat dairy products, fruits and vegetables and therefore high in potassium, magnesium and calcium. These results suggest that a high intake of plant foods in combination with low-fat dairy products may substantially decrease blood pressure and has a greater effect than reductions in sodium intake such as can be achieved in Western societies. Currently the effect of the DASH- diet in combination with sodium reduction is tested in an intervention trial.

\section{Smoking, alcobol and physical activity}

Smoking is the most important determinant of chronic diseases like different cardiovascular diseases, different types of cancer and chronic respiratory diseases. Lopez and Murray calculated that in 1990 world-wide 3.0 million deaths out of a total of 50.5 million could be attributed to tobacco ${ }^{6}$. They projected that this number will increase to 8.4 million by the year 2020. This shows that tobacco is a major killer and that the toll of tobacco smoking will almost triple within a 30-year time period.

The relationships between alcohol consumption, coronary heart disease and stroke mortality are complex. Many studies have shown that persons who do not consume alcohol and those with a high level of consumption are at a higher risk for cardiovascular diseases than moderate alcohol users. In this context also the association between alcohol intake and other causes of death is of importance. The question is what level of alcohol intake is compatible with the lowest mortality.

A large prospective study carried out among US adults showed that cardiovascular mortality was 30 to $40 \%$ lower among persons who reported at least one drink daily compared to non drinkers ${ }^{56}$. All cause mortality was lowest among those who reported one drink daily. These results suggest that a moderate level of alcohol consumption is equivalent to having one drink a day. Also a recently published study carried out in cardiac patients, suggests that one drink per day is associated with the lowest mortality ${ }^{57}$.

The evidence on physical activity and health has been summarised in a report of the Surgeon General of the
$\mathrm{USA}^{58}$. Meta-analyses suggest that in studies of a higher quality the relative risk was 1.8 for persons with the lowest level of physical activity compared with those of the highest level of physical activity. Therefore the American College of Sport Medicine advises to take at least 30 minutes of physical activity e.g. walking and biking, on a daily basis. Because of the high prevalence of inactive people in Western societies an increase in physical activity will have a large public health impact.

This short summary shows that no smoking, moderate alcohol intake and regular physical activity are important components of a healthy life style.

\section{Interactions between genetic and behavioural risk factors}

A positive family history is a risk factor for coronary heart disease. Persons who have a father or mother who died before age 60 from coronary heart disease have a two times higher risk of dying from coronary heart disease compared with persons who do not have a positive family history. These results suggest that genetic factors are an important determinant of an individual's chance to develop coronary heart disease. This has been known for a long time in relation to monogenetic traits like familial hypercholesterolemia. However, monogenetic traits are uncommon in the population. From a public health point of view the polygenetic traits and their interactions with behavioural risk factors are more important because they are much more common in the population.

We studied the interaction between genetic and lifestyle factors e.g. physical activity, alcohol and smoking in relation to blood lipids and lipoproteins ${ }^{59}$. We found that a mutation in the LPL gene (D9N) increased the apo B and LDL cholesterol levels. However, this increase could be counteracted by physical activity. Physically active persons with this mutation had similar apo $\mathrm{B}$ and LDL cholesterol levels compared to persons who did not have this mutation.

We also found that moderate alcohol consumers with the CETP B2B2 genotype had higher HDL cholesterol levels compared with subjects having other genotypes. These results suggest that moderate alcohol consumption strengthens a genetic predisposition for high HDL cholesterol levels. Smokers with the apo C III S1S2 genotype had higher level of triglycerides and apo $\mathrm{B}$ compared with the S1S1 genotype. This was not observed among non-smokers. Smoking may therefore deteriorate the effect of a predisposition to unfavourable lipid levels.

These results suggest that important interactions between genetic and behavioural risk factors in relation to blood lipids exist. To unravel these complex interactions it is necessary to get more insight into the role of different factors in predicting coronary heart disease risk. Ultimately this may lead to more specific advice on behavioural risk factors for persons with certain genetic traits. 


\section{Dietary prevention of cardiovascular diseases}

We have shown that diet is an important determinant of biological risk factors e.g. blood lipids and blood pressure, and of cardiovascular diseases. Some effects of diet are due to an effect on biological risk factors e.g. the effect of fatty acids on serum total and LDL cholesterol but diet can also have effects independent of serum cholesterol e.g. effects of $\mathrm{N}-3$ polyunsaturated fatty acids such as $\alpha$-linolenic acid and eicosapentaenoic acid on e.g. membrane fluidity and ventricular fibrillation. In order to get a complete picture of the effect of dietary interventions the different aspects of diet on biological risk factors and the direct effects of diet on cardiovascular endpoints should be evaluated.

An important point to consider is the difference in effects of diet on biological risk factors and cardiovascular diseases under controlled conditions such as clinical trials and under ordinary living conditions. In this context the terms efficacy (health gain under optimal e.g. trial conditions) and effectiveness (health gain under ordinary living conditions) are of importance. In the latter category the results of both intervention studies under free-living conditions and of trend studies in populations will be dealt with.

In uni and multifactorial intervention trials carried out in the 1960's an 1970's saturated fatty acids were exchanged for poly-unsaturated fatty acids especially linoleic acid ${ }^{60}$. In 14 primary and secondary prevention trials an average reduction in serum total cholesterol of about $10 \%$ was obtained. This was associated with a $13 \%$ reduction in the occurrence of coronary events and a $6 \%$ reduction in all cause mortality. The five trials with the largest serum cholesterol reduction showed an average decrease in serum cholesterol of $13 \%$. This decrease was associated with a 30\% decrease in coronary events and a $11 \%$ decrease in mortality from all causes. Later trials carried out in the 1980's and 1990's did not lower serum cholesterol but intervened on specific fatty acids e.g. by increasing fatty fish consumption (DART-trial), $\alpha$-linolenic acid intake (Lyon trial), by supplementation with eicosapentaenoic acid and docosahexaenoic acid (GISSI-P-trial), or by increasing the consumption of fruits and vegetables (Indian trial) $^{30,34,35,61}$. These trials were carried out in cardiac patients and especially the trials using dietary interventions showed larger effects on coronary heart disease and all cause mortality than the earlier trials on cholesterol lowering. In these trials cardiac mortality was reduced by $33-76 \%$ and all cause mortality by $29-70 \%$. The largest effect was seen on sudden death. These results show clearly that not only cholesterol lowering is of importance. A healthy well balanced diet has more effects than serum cholesterol lowering alone.

What can be achieved by dietary interventions in everyday practice? A recent meta-analysis of 17 randomised controlled trials on dietary behaviour intervention of a least 3 months duration showed a net change in total cholesterol of $-0.22 \mathrm{mmol} / 1$ or approximately $3 \%{ }^{62}$. A decrease of $-45.0 \mathrm{mmol}$ urinary sodium $/ 24$ hours was associated with a non-significant decrease in systolic blood pressure of $-1.9(1 \%)$ and in diastolic blood pressure of $-1.2 \mathrm{mmHg}$ (1\%). These results show that dietary behaviour intervention in primary prevention can achieve modest improvements in diet and biological risk factor status.

These results seem rather disappointing. Only small risk factor reductions can be obtained in free living subjects. However if changes in the dietary pattern of a whole society occur, impressive changes can be obtained. A well-known example in this context is Finland ${ }^{63}$. Between 1972 and 1992 a 13\% decrease in serum cholesterol took place because of the change from butter to vegetable oil margarine's, from whole fat milk to low fat milk and from boiled to filtered coffee. There was also a $9 \%$ decrease in blood pressure probably because of a reduction in sodium intake and an increase in fruit and vegetable consumption. These changes in serum cholesterol and blood pressure contributed for a large extent to the 55\% decline in coronary heart disease mortality in men and the $68 \%$ decline in women.

The results from Finland show that changes in dietary habits in the whole population are probably easier to achieve than changes in the diet of subgroups e.g. high risk persons within a society. If the whole society changes its dietary pattern every person or a large majority changes its behaviour. This is in that case socially acceptable. If only a few high risk persons have to change their diet they have to deviate from the usual dietary pattern in the general population and that is much more difficult to achieve. That impressive changes can be realised in the population can also be shown by results from the Zutphen Study. In 1960 about 70\% of the participants ate white bread. Twenty five years later this percentage was reduced to $30 \%$ and $70 \%$ ate brown or wholemeal bread.

The latest development in relation to food consumption is the introduction of functional foods on the markets. These foods have been enriched with a constituent of which the producer claims that it is of health benefit for the consumer. An example is the introduction of margarine's enriched with plant sterols or stanols. If this spread is used in ordinary amounts the user will get an intake of 1-3 grams of plant sterols or stanols per day. This decreases total and LDL cholesterol by about $10 \%$ and does not influence HDL cholesterol ${ }^{64}$. Because of this total and LDL cholesterol lowering effect the risk of an individual for getting a coronary event may decrease on average by $20-30 \%$.

Can the introduction of functional foods on the market be viewed as a positive development? The advantage as in the case of margarine's enriched with plant sterols or stanols is that the risk of an individual for coronary heart 
disease decreases. There may also be side effects such as the $10-20 \%$ decrease in plasma carotenoids. As far as we know at the moment, plasma carotenoids are not convincingly associated with coronary heart disease or other chronic diseases. However, not all evidence is available yet and we may have to change our opinion in the future. Another aspect to consider in this context is that the average decrease in carotenoids is $10-20 \%$ but in persons with a higher than average bread consumption larger decreases in total and LDL cholesterol and in carotenoids may be obtained by a higher than average intake of the plant sterol containing margarine's. We do not know what the health consequences are of a decrease of e.g. 20-40\% in plasma carotenoids.

Evidence is accumulating that a well balanced diet has a large preventive potential. This means not only a diet low in saturated and trans fatty acids but also regular consumption of fish and a diet rich in plant foods. We have shown in the Finnish, Dutch and Italian cohorts of the Seven Countries Study that men who complied best to a healthy diet indicator based on guidelines of the WHO had the best survival in all three countries ${ }^{65}$. Even in the case of a Mediterranean diet as used in Italy, it was shown that also there a relation exists between the quality of the Mediterranean diet and survival. This was also found in a study from Greece ${ }^{66}$. It is therefore of great importance to define a healthy food pattern.

It is frequently thought that a healthy diet is only of importance in relation to primary prevention of cardiovascular diseases. The secondary prevention trials carried out in cardiac patients have clearly shown that they benefit substantially from dietary changes e.g. an increased consumption of fatty fish, $\alpha$-linolenic enriched margarines, fruit and vegetables ${ }^{30,34,61}$. In these trials the reduction in all cause mortality was larger than in the trials in which statins were used for cholesterol lowering ${ }^{67}$. It may therefore be concluded that a well balanced diet is of importance for both primary and secondary prevention of cardiovascular diseases.

In relation to prevention of cardiovascular diseases a healthy diet is recommended ${ }^{22}$, characterised by

- a low intake of saturated fatty acids (less than 10 percent of energy/day).

- a low intake of trans fatty acids (less than 2 percent/ day)

- at least 4 percent/d of energy of linoleic acid, 2 grams/day $\alpha$-linolenic acid and 200 milligrams/day of very long chain N-3 polyunsaturated fatty acids

- at least 400 grams/day of fruits and vegetables

- a salt intake of less than 6 grams/day.

\section{Conclusions}

This short overview shows that cardiovascular diseases e.g. coronary heart disease and stroke are and will be for the next 20 years the major causes of death in Europe. In spite of decreasing mortality rates the number of cardiovascular patients will increase because of the ageing population and successful treatment. Diet is an important determinant of biological risk factors for cardiovascular diseases e.g. serum cholesterol and blood pressure. However, dietary constituents may also exert an influence on these diseases independent of these risk factors. Based on the results of observational epidemiology, controlled dietary intervention studies and primary and secondary prevention trials it can be concluded that a diet low in saturated and trans fatty acids and rich in plant foods in combination with regular fish consumption is associated with the lowest risk for cardiovascular and all cause mortality. Diet is not the only behavioural risk factor of importance in this context. In addition to a well balanced diet, the advice should be not to smoke, to use alcohol in moderation and to stay physically active. If this advice is put into practice both quantity and quality of life of both persons free of cardiovascular diseases and of cardiovascular patients can be improved.

\section{Acknowledgements}

Dr. Kari Kuulasmaa, head of the MONICA Data Center, National Institute of Public Health, Helsinki, Finland was instrumental in putting together Tables $1-3$. His help and the approval of the MONICA Steering Committee and Principal Investigators to use their risk factor data is gratefully acknowledged.

\section{References}

1 Sans S, Kesteloot H, Kromhout D on behalf of the Task Force. The burden of cardiovascular diseases mortality in Europe. Task force of the European Society of Cardiology on Cardiovascular Mortality and Morbidity Statistics in Europe. Eur. Heart J. 1997; 18: 1231-48.

2 Tunstall Pedoe H, Kuulasmaa K, Amoyal P, Arvieler D, Rajakangas AM, Pajak A. Myocardial infarction and coronary deaths in the World Health Organisation MONICA project. Circulation 1994; 90: 583-612.

3 Van der Pal-de Bruin KM, Verkleij H, Jansen J, Bartelds A, Kromhout D. The incidence of suspected myocardial infarction in Dutch general pratice in the period 19781994. Eur. Heart J. 1998; 19: 427-32

4 Public Health Status and Forecasts. Health, prevention and health care in the Netherlands until 2015. Ruwaard D, Kramers PGN (Eds.) Elsevier/De Tijdstroom, Maarssen, The Netherlands ISBN: 90-352-2040-4. 1997.

5 Murray CJL, Lopez AD. Mortality by cause for eight regions of the world: Global Burden of Disease Study. Lancet 1997; 349: 1269-76.

6 Murray CJL, Lopez AD. Alternative projections of mortality and disability by cause 1990-2020. Global Burden of Disease Study. Lancet 1997; 349: 1498-504.

7 Murray CJL, Lopez AD. Global mortality, disability and the contribution of risk factors: Global Burden of Disease Study. Lancet 1997; 349: 1436-42.

8 Steinberg D, Parthasarathy S, Carew TE, Khoo JC, Witzum JL. Beyond cholesterol. Modifications of low-density lipoprotein 
that increase its atherogenicity. N. Engl. J. Med. 1989; 320: 915-24.

9 Anderson KM, Odell PM, Wilson PWF, Kannel WB. Cardiovascular disease risk profiles. Am. Heart J. 1990; 121: 293-8.

10 MacMahon S, Peto R, Cutler J, Collins R, Sorlie P, Neaton J, Abbott R, Godwin J, Dyer A, Stamler J. Blood pressure, stroke, and coronary heart disease. Part 1, Prolonged differences in blood pressure: prospective observational studies corrected for the regression dilution bias. Lancet 1990; 335: 765-74.

11 Collins R, Peto R, MacMahon S, Hebert P, Fiebach N, Eberlein K, Godwin J, Qiziibash N, Taylor J, Hennekens C. Blood pressure, stroke and coronary heart disease. Part 2: shortterm reductions in blood pressure: overview of randomized drug trials in their epidemiological context. Lancet 1990; 335: 827-38.

12 Hoogen PCW van den, Feskens EJM, Nagelkerke NJD, Menotti A, Nissinen A, Kromhout D.for the Seven Countries Study Research Group. Blood pressure, hypertension and long-term coronary heart disease mortality in different populations. New Eng. J. Med. 2000; 342: 1-8.

13 Seidell JC, Verschuren WMM, van Leer EM, Kromhout D. Overweight, underweight, and mortality: A prospective study of 48287 men and women. Arch. Intern. Med. 1996; 156: 958-63.

14 Keys A, ed. Seven countries. A multivariate analysis of death and coronary heart disease. Cambridge, MA: Harvard University Press, 1980

15 Rayner M, Petersen S. Compilers European cardiovascular disease statistics. London: British Heart Foundation, 2000.

16 Kuulasmaa K, Tunstall-Pedoe H, Dobson A, Fortmann S, Sans S, Tolonen H, Evans A, Ferrario M, Tuomilehto J. Estimation of contribution of changes in classic risk factors to trends in coronary-event rates across the WHO MONICA Project populations. Lancet 2000; 355: 675-87.

17 Kromhout D, Nissinen A, Menotti A, Bloemberg B, Pekkanen J, Giampaoli S. Total and HDL cholesterol and their correlates in elderly men in Finland, Italy and the Netherlands. Am. J. Epidemiol. 1990; 131: 855-63.

18 Kromhout D, Nedeljkovic SI, Grujic MZ, Ostojic MC, Keys A, Menotti A, Katan MB, Van Oostrom MA, Bloemberg BPM. Changes in major risk factors for cardiovascular diseases during 25 years in the Serbian cohorts of the Seven Countries Study. Int. J. Epidemiol. 1994; 23: 5-11.

19 Keys A. Blood lipids in man - a brief review. J. Am. Diet. Ass. 1967; 51: 508-16.

20 Clarke R, Shipley M, Lewington S, Youngman L, Collins R, Marmot M, Peto R. Underestimation of risk associations due to regression dilution in long-term follow-up of prospective studies. Am. J. Epidemiol. 1999; 150: 341-53.

21 Verschuren WMM, Jacobs DR, Bloemberg BPM, Kromhout D, Menotti A, Aravanis C, Blackburn HW, Buzina R, Dontas AS, Fidanza F, Karvonen MJ, Nedeljkovic S, Nissinen A, Toshima H. Serum total cholesterol and long-term coronary heart disease mortality in different cultures. Twenty-five year follow-up of the Seven Countries Study. JAMA 1995; 274: 131-6.

22 Wood D, DeBacker G, Faergeman O, Graham I, Mancia G, Pyörälä $K$ together with members of the Task Force. Prevention of coronary heart disease in clinical practice Recommendations of the second joint task force of European and other Societies on Coronary prevention. Eur. Heart J. 1998; 19: 1434-503.

23 Kromhout D. On the waves of the Seven Countries Study. A public health perspective on cholesterol. Eur. Heart J. 1999; 20: 796-802.

24 Kromhout D, Menotti A, Bloemberg B, Aravanis C, Blackburn H, Buzina R, Dontas AS, Fidanza F, Giampaoli S, Jansen A, et al. Dietary saturated and trans fatty acids, cholesterol and 25-year mortality from coronary heart disease. The Seven Countries Study. Prev. Med. 1995; 24: 308-15.

25 Hu FB, Stampler MJ, Manson JE, Rimm E, Colditz GA, Rosner BA, Hennekens CH, Willett WC. Dietary fat intake and risk of coronary heart disease in women. N. Engl. J. 1997; 337: 1491-9.

26 Ascherio A, Katan MB, Zock PL, Stampfer MJ, Willett WC. Trans fatty acids and coronary heart disease. Sounding Board. N. Engl. J. Med. 1999; 340: 1994-8.

27 Willett WC, Stampfer MJ, Manson JE, Colditz GA, Speizer FE, Rosner BA, Sampson LA, Hennekens CH. Intake of trans fatty acids and risk of coronary heart disease among women. Lancet 1993; 341: 581-5.

28 Katan MB, Grundy SM, Willett WC. Beyond low-fat diets. $N$. Engl. J. Med. 1997; 337: 563-6.

29 Hu FB, Stampfer MJ, Manson JAE, Rimm EB, Wolk A, Colditz GA, Hennekens C, Willett WC. Dietary intake of $\alpha$-linolenic acid and risk of fatal ischemic heart disease among women. Am. J. Clin. Nutr. 1999; 69: 890-7.

30 Lorgeril M de, Renaud S, Mamelle N, Salen P, Martin J-L, Monjaud I, Guidollet J, Touboul P, Delaye J. Mediterranean alpha-linolenic acid-rich diet in secondary prevention of coronary heart disease. Lancet 1994; 343: 1454-9.

31 Kromhout D, Bosschieter EB, De Lezenne Coulander C. The inverse relation between fish consumption and 20-year mortality from coronary heart disease. N. Engl. J. Med. 1985; 312: 1205-9.

32 Kromhout D, Feskens EJM, Bowles CH. The protective effect of a small amount of fish on coronary heart disease mortality in an elderly population. Int. J. Epidemiol. 1995; 24: 340-5.

33 Marckmann P, Gronbaek M. Fish consumption and coronary heart disease mortality. A systematic review of prospective cohort studies. Eur. J. Clin. Nutr. 1999; 53: 585-90.

34 Burr ML, Fehily AM, Gilbert JF, Rogers S, Holliday RM, Sweetnam PM, Elwood PC, Deadman NM. Effects of changes in fat, fish and fibre intakes on death and myocardial reinfarction: diet and re-infarction trial (DART). Lancet 1989; ii 757-61.

35 GISSI-Prevenzione Investigators* (Gruppo Italiano per lo Studio della Sopravvivenza nell'Infarto miocardico). Dietary supplementation with n-3 polyunsaturated fatty acids and vitamin $\mathrm{E}$ after myocardial infarction: results of theGISSIPrevenzione trial. Lancet 1999:354: : 447-55.

36 Stampfer MJ, Hennekens CH, Manson JE, Colditz GA, Rosner $\mathrm{B}$, Willett WC. Vitamin E consumption and the risk of coronary disease in women. N. Engl. J. Med. 1993; 328: 1444-9.

37 Rimm EB, Stampfer MJ, Ascherio A, Giovanucci E, Colditz GA, Willett WC. Vitamin E consumption and the risk of coronary disease in men. N. Engl. J. Med. 1993; 328: 1450-7.

38 Losonczy KG, Harris TB, Havlik RJ. Vitamin E and Vitamin C supplement use and risk of all-cause and coronary heart disease mortality in older persons: the Establised Populations for Epidemiologic Studies of the Elderly. Am. J. Clin. Nutr. 1996; 64: 190-6.

39 Kushi LH, Folsom AR, Prineas RJ, Mink PJ, Wu Y, Bostick RM. Dietary antioxidant vitamins and death from coronary heart disease in postmeopausal women. N. Engl.J. Med. 1996; 334 1156-62.

40 Knekt P, Reunanen A, Järvinen R, Seppänen R, Heliövara M, Aromaa A. Antioxidant vitamin intake and coronary mortality in a longitudinal population study. Am. J. Epidemiol. 1994; 139: 1180-9.

41 Stephens NG, Parsons A, Schofield PM, Kelly F, Cheeseman K, Mitchinson MJ, Brown MJ. Randomised controlled trial of vitamin $\mathrm{E}$ in patients with coronary disease: Cambridge Heart Antioxidant Study (CHAOS). Lancet 1996; 347: 781-6.

42 The Heart Outcomes Prevention Evaluation Study Investigators. Vitamin E supplementation and cardiovascular events in high-risk patients. N. Engl. J. Med. 2000; 342: 154-60. 
43 Pandey DK, Shelleke R, Selwyn BJ, Tangney C, Stamler J. Dietary vitamin $C$ and $\beta$-carotene and risk of death in middle -aged men. The Western Electric Study. Am. J. Epidemiol. 1995; 142: 1269-78.

44 The Alpha-Tocopherol, Beta Carotene Cancer Prevention Study Group. The effect of vitamin E and beta carotene on the incidence of lung cancer and other cancers in male smokers. N. Engl. J. Med. 1994; 330: 1029-35.

45 Omenn GS, Goodman GE, Thornquist MD, Balmes J, Cullen MR, Glass A, Keogh JP, Meyskens FLJr, Valanis B, Williams JHJr, Barnhart S, Hammar S. Effects of combination of beta carotene and vitamin A on lung cancer and cardiovascular disease. N. Engl. J. Med. 1996; 334: 1150-5.

46 Hennekens CH, Buring JE, Manson JE, Stampfer M, Rosner B, Cook NR, Belanger C, LaMotte F, Gaziano JM, Ridker PM, Willett W, Peto R. Lack of effect of long-term supplementation with beta carotene on the incidence of malignant neoplasms and cardiovascular disease. N. Engl. J. Med. 1996; 334: 1145-9.

47 Hertog MGL, Feskens EJM, Hollman PCH, Katan MB, Kromhout D. Dietary antioxidant flavonoids and risk of coronary heart disease. The Zutphen Elderly Study. Lancet 1993; 342: 1007-11.

48 Knekt P, Järvinen R, Reunanen A, Maatela J. Flavonoid intake and coronary mortality in Finland: a cohort study. BMJ 1996; 312: $478-81$.

49 Rimm EB, Katan MB, Ascherio A, Stampfer MJ, Willett WC. Relation between intake of flavonoids and risk for coronary heart disease in male health professionals. Ann. Intern. Med. 1996; 125: 384-9.

50 Hertog MGL, Sweetman PM, Fehily AM, Elwood PC, Kromhout D. Antioxidant flavonoids and ischaemic heart disease in a Welsh population of men. The Caerphilly Study. Am. J. Clin. Nutr. 1997; 65: 1489-94.

51 Kromhout D, Bloemberg BPM, Feskens EJM, Hertog MGL, Menotti A, Blackburn $H$ for the Seven Countries Study Group. Alcohol, fish, fiber and antioxidant vitamins do not explain population differences in coronary heart disease mortality. Int. J. Epidemiol 1996; 25(4): 753-9.

52 Hertog MGL, Kromhout D, Aravanis C, Blackburn H, Buzina R, Fidanza F, Giampaoli S, Jansen A, Menotti A, Nedeljkovic $S$, Pekkarinen M, Simic BS, Toshima H, Feskens EJM, Hollman $\mathrm{PCH}$, Katan MB. Flavonoid intake and long-term risk of coronary heart disease and cancer in the Seven Countries Study. Arch. Intern. Med. 1995; 155: 381-6.

53 INTERSALT Cooperative Research Group. INTERSALT: an international study of electrolyte excretion and blood pressure. Results for 24 hour urinary sodium and potassium excretion. Brit. Med. J. 1988; 297: 319-28.
54 Taubes G. The (political) science of salt. Science 1998; 281: 898-907.

55 Appel LJ, Moore TG, Obarzanek R, Vollmer WM, Svetkey LP, Sacks FM, Bray GA, Vogt TM, Cutler JA, Windhauser MM, Lin $\mathrm{PH}$, Karanja N. A clinical trial of effects of dietary patterns on blood pressure. N. Engl. J. Med. 1997; 336: 1117-24.

56 Thun MJ, Peto R, Lopez AD, Monaco JH, Henley J, Heath CW, Doll R. Alcohol consumption and mortality among middleaged and elderly US adults. N. Engl. J. Med. 1997; 337: 170514.

57 Muntwyler J, Hennekens CH, Buring JE, Gaziano JM. Mortality and light to moderate alcohol consumption after myocardial infarction. Lancet 1999; 352: 1882-5.

58 US Department of Health and Human Services. Physical activity and health. A report of the surgeon general. Atlanta GA Center for Disease Control and Prevention. National Center for Chronic Disease Prevention and Health Promotion, 1996.

59 Boer J, Coronary heart disease risk Family history and geneenvironment interaction. PhD thesis. ISBN 90-5808-034-X. Wageningen, The Netherlands: 1999

60 Truswell AS. Review of dietary intervention studies: effect on coronary events and mortality. Aust. NZ. J. Med. 1994; 24: 98-106.

61 Singh RB, Rastogi SS, Verma R, Laxmi B, Singh R, Ghosh S, Niaz MA. Randomised controlled trial of cardioprotective diet in patients with recent acute myocardial infarction: results of one year follow up. BMJ 1992; 304: 1015-9.

62 Brunner E, White I, Thorogood M, Bristow A, Curle D, Marmot M. Can dietary interventions change diet and cardiovascular risk factors?. A meta-analysis of randomized controlled trials. Am. J. Publ. Hlth. 1997; 87: 1415-22.

63 Vartiainen E, Puska P, Pekkanen J, Tuomilehto J, Jonsilakti P. Changes in risk factors explain ischaemic heart disease in Finland. Brit. Med. J. 1994; 309: 23-7.

64 Law M. Plant sterol and stanol margarines and health. BMJ 2000; 320: 861-4.

65 Huijbregts P, Feskens E, Räsänen L, Fidanza F, Nissinen A, Menotti A, Kromhout D. Dietary pattern and 20 year mortality in elderly men in Finland, Italy, and the Netherlands: Longitudinal cohort study. Br. Med.J. 1997; 315: 13-7.

66 Trichopoulou A, Kouris-Blazos A, Wahlqvist ML, Gnardellis C, Lageou P, Polychronopoulos E, Vassilakou T, Lipworth L, Trichopoulos D. Diet and overall survival in elderly people. Brit. Med.J. 1995; 311: 1457-60.

67 LaRosa JC, He J, Vupputuri S. Effect of statins on risk of coronary disease a meta-analysis of randomized controlled trials. JAMA 1999; 24: 2340-6. 